\title{
Preliminary study on the distribution of partial edentations in a batch of young adults
}

\author{
George Ion ${ }^{1}$, Rodica Luca ${ }^{2}$, Carmen Nicolae ${ }^{3}$, Elena Claudia Coculescu ${ }^{3}$ \\ ${ }^{1}$ Fixed Prosthetics Department, Faculty of Dental Medicine, \\ "Carol Davila" University of Medicine and Pharmacy, Bucharest, Romania \\ ${ }^{2}$ Pedodontics Department, Faculty of Dental Medicine, \\ "Carol Davila" University of Medicine and Pharmacy, Bucharest, Romania \\ ${ }^{3}$ Oral Pathology Department, Faculty of Dental Medicine, \\ "Carol Davila" University of Medicine and Pharmacy, Bucharest, Romania
}

\begin{abstract}
Objective. The purpose of the study was to analyze the distribution of partial edentation in the young adult. Material and method. The study was conducted on a batch of young adult patients examined between 20152016. Their social and demographic data odontal status were recorded for each patient. The criterion of inclusion in the study was the presence of at least one edentation. The data obtained were statistically processed in SPSS 13.0 for Windows.

Results. Out of the 162 patients between 18 and 35 years of age (average age 27.01+/- 5.09 years, the 21-22 years of age group being best represented), 147 (70 male and 77 female) showed at least one edentation. The average number of edentations per patient was 2.17 (2.03 for female patients and 2.31 for males). Most edentate breaches were of one tooth. According to Kennedy classification, most edentations were class III, followed in decrease order by class I, II and IV. There was no statistically significant difference between the presence of the edentation and the patient's gender $(p=0.788)$, the origin environment $(p=0.825)$ or the education level $(p=$ $0.577)$. In $116(78.91 \%)$ cases, decay was the main cause of edentation.

Conclusions. Approximately $91 \%$ of young adults showed at least one partial edentation, the most frequent form being Kennedy III class. The high prevalence of partial edentations among young adults emphasizes the importance and the need of enforcing preventative methods or decay treatment in their early stages.
\end{abstract}

Keywords: partial edentation, young adult

\section{INTRODUCTION}

The edentation of young adult is frequent and increasing, with direct functional consequences and sometimes with serious socio-professional implications. The higher and higher frequency of partial edentations in the young adult, due in particular to the complications of odontal injuries as well as traumas (sports, car accidents, human violence etc.), implies a certain therapeutic attitude with the individualization of the treatment plan and the chosen therapeutic solutions.

There are studies in the specialized literature on partial edentation in various age categories includ- ing individuals aged 19-26 years (1) or aged 15-64 (2) or the age of 35 (3) as reference point. In exchange, for the 18-35 years of age group, the age group assigned for the first time to the young adult by psychologist Erik Erikson in the early 60s (4), references are missing. For this reason, the purpose of this paper is to analyze the distribution of partial edentation in the young adult between the ages of 18 and 35.

Regarding the terminology used to define partial edentations, there is still no generally valid consensus. Thus, over time, a concern of the specialists was to organize an as simple as possible and more efficient system to localize, name, classify and 
communicate partial edentations. The first publication containing a systematization of the clinical forms of partial edentations belongs to Cummer in 1921 (5). This first classification with direct reference to treatment solutions (by disjunctive prosthesis), contains 4 classes of edentation dependent on the position of the direct keeping elements (hooks) of the partial movable prostheses. Over time, more than 100 such classifications have been proposed, depending on the extent of the edentate breach (6), their topography (7), the type of prosthetic support or other criteria (8). Nevertheless, the most widespread is the Kennedy classification $(9,10)$, a classification based on the topographic criterion of edentations, class I includes the lateral bi-terminal edentation, the second class the uniterminal edentation, the third class the intercalated one (the lateral area), and the fourth class the front one. Any other extra edentation is called "modification".

\section{MATERIAL AND METHOD}

This study included all young adults aged between 18 and 35 who asked for dental care between 2015-2016 in two dental offices, one in the urban environment, the second one in the rural environment (the first office in Bucharest, the second one in Ilfov county).

Each patient had their observation sheet prepared with their socio-demographic data (age, gender, background, education level) and odontal status. The inclusion criterion in the study group was the presence of at least one partial edentation.

The presence, topography and the possible cause of the edentations encounters in the patients included in the study was analyzed according to the socio-demographic variables mentioned above. The data obtained were centralized and statistically processed in SPSS - Statistical Package for the Social Sciences version 13.0 for Windows.

\section{RESULTS}

A number of 162 patients aged 18 to 35 have been checked, the average age being $27.01+/-5.09$ years. Of the total patients examined, $15(9.26 \%)$ did not have any edentation and 147 (90.74\%) had at least one partial edentation. Consequently, the study batch consisted of these 147 patients who presented at least one partial edentation. a) The composition of the study batch according to the social and demographic factors.

The batch comprised 70 male patients $(47.62 \%)$ and 77 female (52.38\%) (Fig. 1). The average age of the male patients was $28.26+/-4.72$ years and of the female $25.88+/-5.18$ years. The maximum number of patients with partial edentations (24) was recorded at the age of 22 years (Fig. 2).

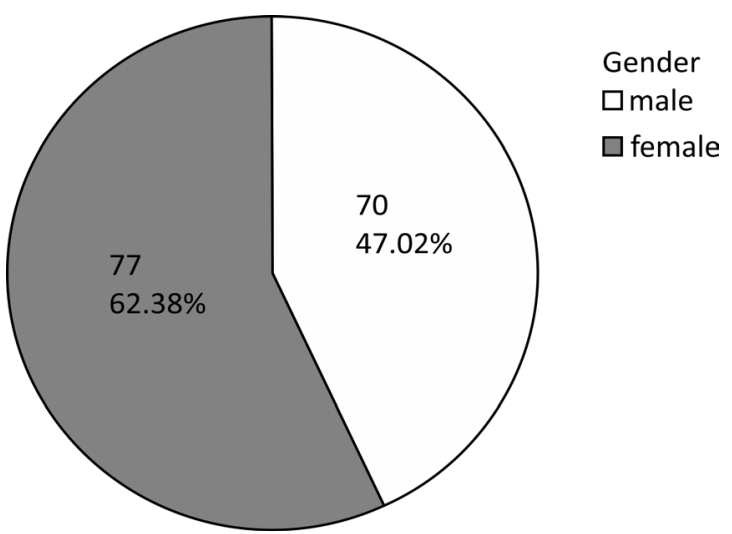

FIGURE 1. Patients' distribution according to gender ( $n$, \%)

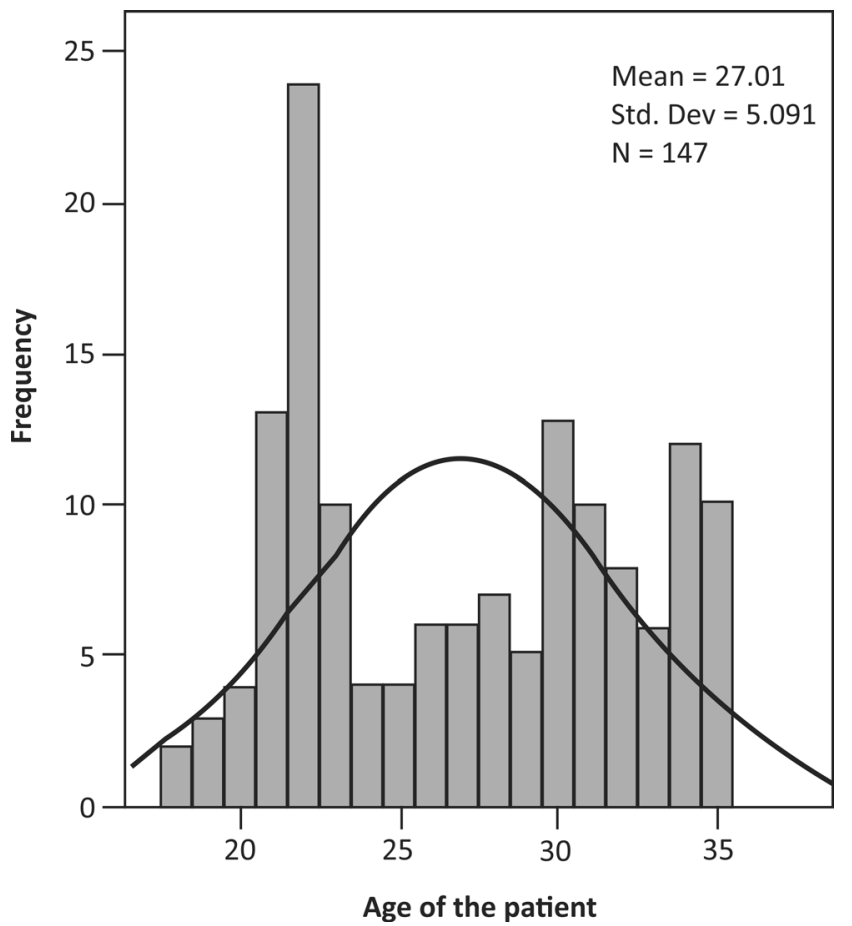

FIGURE 2. Patients' distribution according to age

The patients came both from urban and rural environments. Table 1 which shows the distribution according to the environment of origin, shows the higher number of urban patients compared to the number of those from the rural environment. In terms of gender-based distribution, in the urban environment, the number of male patients is almost 
equal to that of female patients, while in the rural environment, females predominate.

TABLE 1. Patients' distribution according to the origin environment

\begin{tabular}{|l|l|c|c|c|c|c|c|}
\hline \multirow{2}{*}{ Patients } & \multicolumn{4}{|c|}{ Environment } & \multicolumn{2}{c|}{ Total } \\
\cline { 3 - 8 } \multicolumn{2}{|l|}{} & \multicolumn{2}{|c|}{ Rural } & \multicolumn{2}{c|}{ Urban } & \multicolumn{2}{c|}{} \\
\cline { 2 - 8 } \multicolumn{2}{|l|}{} & $\mathbf{n}$ & $\mathbf{\%}$ & $\mathbf{n}$ & $\%$ & $\mathbf{n}$ & $\%$ \\
\hline Gender & male & 17 & 11.56 & 53 & 36.05 & 70 & 47.61 \\
\hline & female & 26 & 17.69 & 51 & 34.70 & 77 & 52.38 \\
\hline Total & 43 & 29.25 & 104 & 70.75 & 147 & 100 \\
\hline
\end{tabular}

As a level of education, 12 patients $(8.20 \%)$ graduated from gymnasium, $85(57.80 \%)$ high school, and 50 (34\%) had higher education. The distribution according to the level of education and patient's gender is shown in Fig. 3.

Education level $\square$ Gymnasium

$\square$ High school

$\square$ Higher education

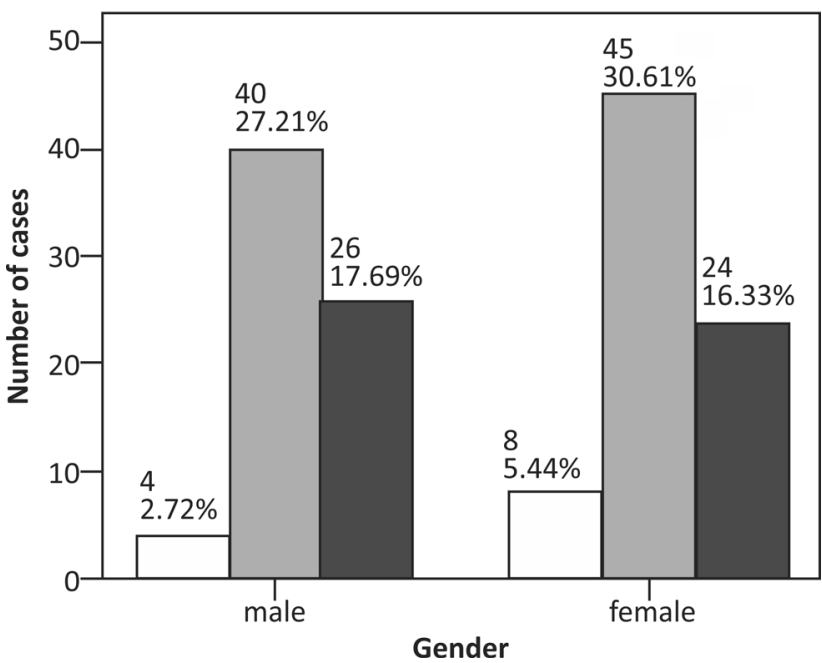

FIGURE 3. Patients' distribution according to education level

a) Distribution / frequency of partial edentation

The 147 patients had 319 edentations. The average number of edentations per patient was 2.17. In female patients the average number was 2.03 and 2.31 for males.

Irrespective of the number of participants in the study (high number of patients around the age of 22-23 years and 30-31 years), the distribution of the average number of edentations is flat, around 2.17 (Fig. 4).

There was no statistically significant difference between the presence of edentation and the patient's gender $(p=0.788)$ or the origin environment $(p=0.825)$. Also, there was also no statistically sig- nificant correlation between the presence of edentations and the degree of education $(\mathrm{p}=0.577, \mathrm{p}>$ 0.05) (Table 2).

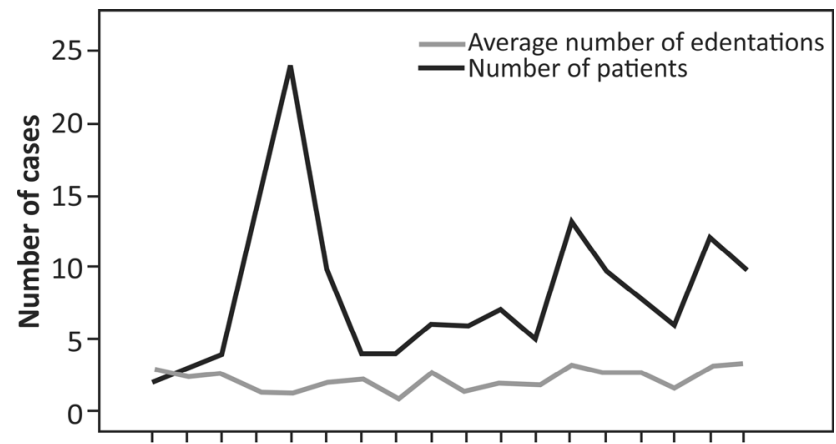

181920212223242526272829303132333435

age

FIGURE 4. Distribution of average number of edentations according to age

TABLE 2. Correlation test of Spearman ranks

\begin{tabular}{|l|l|l|c|c|}
\hline \multicolumn{2}{|l|}{ Correlations } & $\begin{array}{c}\text { Education } \\
\text { level }\end{array}$ & Edentation \\
\hline $\begin{array}{l}\text { Spearman } \\
\text { rank, } \\
\text { correlation }\end{array}$ & $\begin{array}{l}\text { Education } \\
\text { level }\end{array}$ & $\begin{array}{l}\text { Correlation } \\
\text { coefficient }\end{array}$ & 1.000 & .046 \\
\hline & & Sig. (2-tailed) &. & .577 \\
\hline & & $\mathrm{N}$ & 147 & 147 \\
\hline & Edentation & $\begin{array}{l}\text { Correlation } \\
\text { coefficient }\end{array}$ & .046 & 1.00 \\
\hline & & Sig. (2-tailed) & .577 &. \\
\hline & & $\mathrm{N}$ & 147 & 147 \\
\hline
\end{tabular}

b) Types of partial edentations

According to the topographic area, $8(5.44 \%)$ patients presented front edentation, $126(85.71 \%)$ lateral edentation and 13 (8.84\%) mixed edentation. The causes that led to edentations were in decreasing order: dental caries in $116(78.91 \%)$ cases, dento-periodontal traumas in $13(8.84 \%)$ cases and other causes (orthodontic extractions, dental inclusions, etc.) in $18(12.24 \%)$ cases (Table 3$)$.

TABLE 3. Topography and causes of partial edentations

\begin{tabular}{|l|c|c|c|c|c|c|c|c|}
\hline \multirow{2}{*}{ Edentation } & \multicolumn{6}{|c|}{ Cause } & \multicolumn{2}{|c|}{} \\
\cline { 2 - 9 } & \multicolumn{2}{|c|}{ Decay } & \multicolumn{2}{c|}{ Trauma } & \multicolumn{2}{c|}{$\begin{array}{c}\text { Other } \\
\text { causes }\end{array}$} & \multicolumn{2}{|c|}{ Total } \\
\cline { 2 - 10 } & $\mathrm{n}$ & $\%$ & $\mathrm{n}$ & $\%$ & $\mathrm{n}$ & $\%$ & $\mathrm{n}$ & $\%$ \\
\hline Frontal & 0 & 0 & 3 & 2.04 & 5 & 3.40 & 8 & 5.44 \\
\hline Lateral & 108 & 73.46 & 9 & 6.12 & 9 & 6.12 & 126 & 85.71 \\
\hline $\begin{array}{l}\text { Frontal + } \\
\text { Lateral }\end{array}$ & 8 & 5.44 & 1 & 0.68 & 4 & 2.72 & 13 & 8.84 \\
\hline Total & 116 & 78.91 & 13 & 8.84 & 18 & 12.24 & 147 & 100 \\
\hline
\end{tabular}

Fig. 5 and 6 illustrate the distribution of edentations according to the Kennedy classification, without 
taking into consideration the changes in each class. Fig. 5 shows edentations located at the maxillary, and Fig. 6 shows edentations located on the mandible.

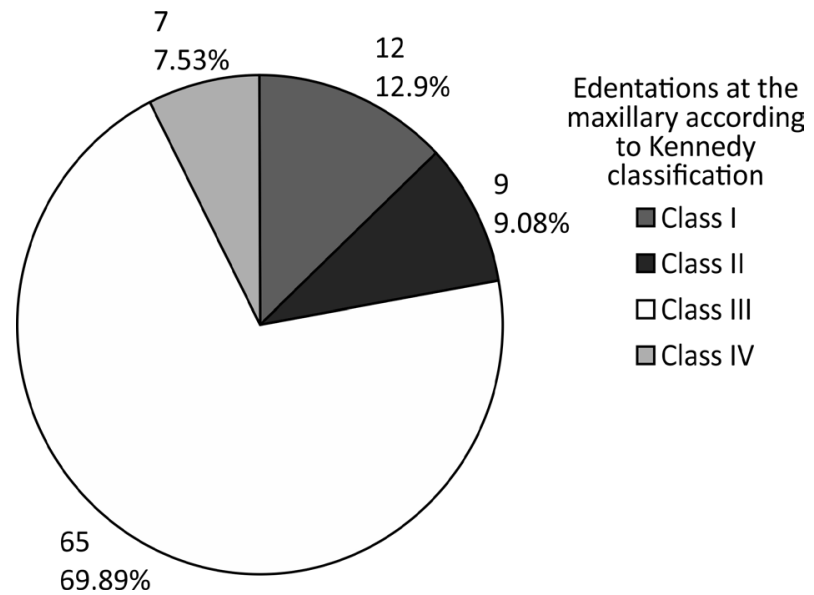

FIGURE 5. Distribution of edentations at the maxillary according to Kennedy classification ( $n, \%)$

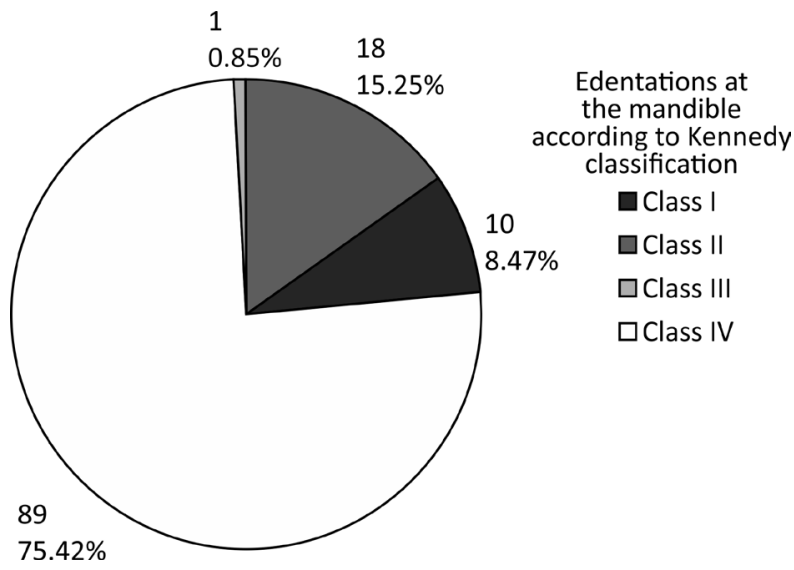

FIGURE 6. Distribution of edentations at the mandible according to Kennedy classification ( $n, \%)$

Most edentations according to Kennedy classification, regardless of their topography, are class III edentations, in decrease order followed by those of class I, II and IV (Table 4).

TABLE 4. Distribution of edentations according to Kennedy classification

\begin{tabular}{|c|c|c|}
\hline Kennedy class & Maxillary \% & Mandible \% \\
\hline I & 12.9 & 15.25 \\
\hline II & 9.68 & 8.47 \\
\hline III & 69.89 & 75.42 \\
\hline IV & 7.53 & 0.85 \\
\hline
\end{tabular}

c) Dimension of edentate breaches

Patients had one or more edentate breaches, 2.17 in average, as specified in point $b$. The number of missing teeth in a breach ranged from 1 to 4 (Fig. 7).

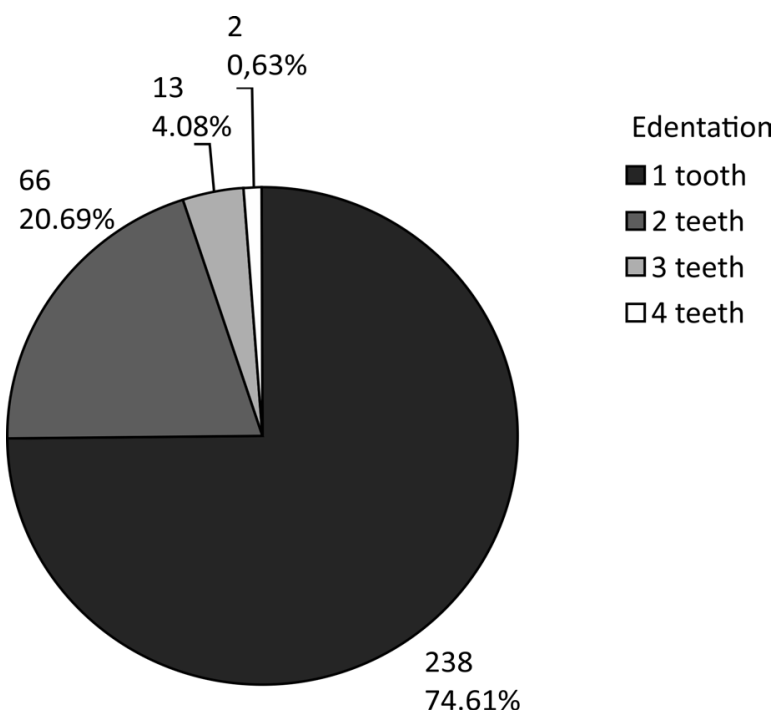

FIGURE 7. Distribution of edentations according to missing teeth $(n, \%)$

Most of the edentate breaches were of one tooth, their distribution according to their location on the maxillary or mandible is presented in Table 5 and Fig. 8.

\section{DISCUSSIONS}

Out of the original batch of 162 young adult patients aged 18 to 35 who addressed the two offices during 2015-2016, only patients who had edentations were selected, so that the final study batch consisted of 147 patients.

The presence and distribution of edentations was analyzed according to several social and demographic factors: patients' age and gender, level of education, origin environment - urban / rural.

The average number of edentations / patient was 2.17. Regardless of the number of patients in each annually estimated age range, the average number of edentations per patient remained flat, around the average value (Figure 4). This finding, also cor-

TABLE 5. Localization of one-tooth edentation $(n=239)$.

\begin{tabular}{|l|c|c|c|c|c|c|c|}
\hline & M2 & M1 & Pm2 & Pm1 & C & IL & IC \\
\hline Maxillary & $6(5.35 \%)$ & $34(30.38 \%)$ & $21(18.75 \%)$ & $31(27.67 \%)$ & $2(1.78 \%)$ & $14(12.50 \%)$ & $4(3.57 \%)$ \\
\hline Mandible & $11(8.66 \%)$ & $100(78.74 \%)$ & $10(7.87 \%)$ & $4(3.14 \%)$ & - & - & $2(1.57 \%)$ \\
\hline Total & $17(7.11 \%)$ & $134(56.07 \%)$ & $31(12.97 \%)$ & $35(14.64 \%)$ & $2(0.84 \%)$ & $14(5.86 \%)$ & $6(2.51 \%)$ \\
\hline
\end{tabular}




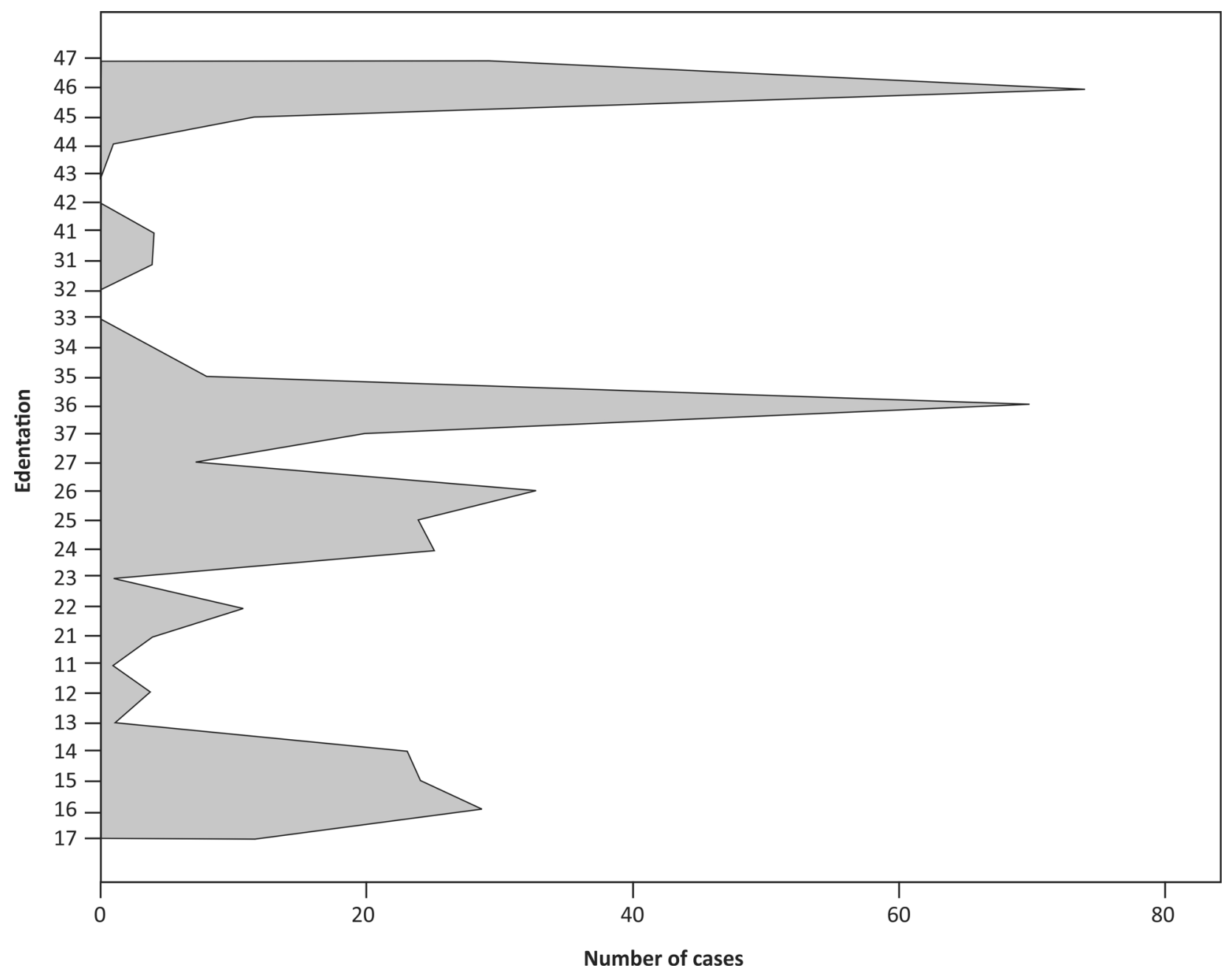

FIGURE 8. Distribution of one-tooth edentations

roborated with the most frequent absence of the first permanent molar at both arches, associated with the loss of the first premolar at the maxillary and the twelve-year molar at the mandible, could highlight the idea that the critical period for the occurrence of edentations, begun in adolescence, extends until the beginning of the age range which characterizes the young adult category. The fact that at the age of 18 edentation is already present contravenes the WHO objectives which, even for 2010 , proposed that no dental extraction be performed at this age (11).

There was no statistically significant difference between the presence of edentation and the gender of the patients, their origin environment or their education.

The patients in the study showed all clinical forms of edentation. According to the Kennedy classification, the most frequent forms, both in the maxillary and in the mandible, were the class III edentations, followed in decreasing order by class I, class II and class IV. Similar results were presented as well by Bharathi M et al. (2013). They reported the presence of the Kennedy class III edentation in $62 \%$ of the cases, class I at $18 \%$, class II at $11 \%$, and class IV in $9 \%$ (12).

Comparing the frequency of edentations in the maxillary and the mandible, edentations of class II and class IV were more frequent in the maxillary than in the mandible, while class III and class I edentations were more frequent in the mandible. In the data published by Patel JY et al. (2014) one may find the same order also observed by us regarding the frequency of edentations in the mandible, but in the maxillary, they found that the most frequent were class III edentations, followed by class II, and only then by class I (10) (Table 6).

According to the number of absent teeth, most edentate breaches were of one tooth. As distribution, at the maxillary, most one-tooth breaches re- 
sulted from the extraction of the first molar, followed by the extraction of the first premolar, then of the second premolar. Similarly, in the mandible, the most frequent one-tooth breaches were due to the extraction of the first molar, followed by the extraction of the second molar, then of the second premolar and of the first premolar. It should be noted that no patient presented the absence of the canine or of the mandibular lateral incisor.

TABLE 6. Distribution of edentations according to Kennedy classification (Patel et al., 2014)

\begin{tabular}{|c|c|c|}
\hline Kennedy Class & $\begin{array}{c}\text { Maxillary } \\
\%\end{array}$ & $\begin{array}{c}\text { Mandible } \\
\%\end{array}$ \\
\hline I & 9.9 & 23.3 \\
\hline II & 24.6 & 10.7 \\
\hline III & 56 & 58 \\
\hline IV & 9.5 & 8 \\
\hline
\end{tabular}

Decay was the most frequent cause of edentations, almost $80 \%$ of all edentations had this etiology. In the case of Kennedy class IV edentations, the least frequent form of edentation encountered in both maxillaries, they were the consequence either of tooth loss because of traumas (in the maxillary) or agenesia (mandible). Basno et al. (2016), in a study on a batch of 334 young adults run over a period of 7 years, found that $73-89 \%$ of the cases had de decay as etiology, 3.4-13.6\% anodontia and
$1.2 \%$ trauma (1). In our study, traumas were involved in a much higher proportion $(8.84 \%)$ in the occurrence of frontal edentations.

\section{CONCLUSIONS}

Approximately $91 \%$ of young adults had at least one partial edentation.

The average number of edentations / patient was 2.17 and there was no statistically significant difference between the number of edentations and the gender of the patients, their origin environment or their education level.

Regardless of it localization in the maxillary or mandible, the Kennedy class III edentation was the most frequent form of edentation and was mainly caused by the loss of the first permanent molar.

The increased prevalence of partial edentations among young adults as well as the main cause of tooth loss (decays and complications) highlights the importance and necessity of enforcing preventative methods or, if the case, of the decay treatment in their early stages to avoid complications that may eventually terminate in the tooth loss. It also generally highlights the importance of public awareness of attending dental checks and, above all, the importance of these checks in children and teenagers.

\section{$\overline{\text { REFERENCES }}$}

1. Basno A, Maxim A, Sain C, Balcoș C, Tatarciuc MS. Prevalence of edentulism and related social-behavioural factors among young adults of laşi, Romania. International Journal of Medical Dentistry, 2016. 6(3):214-222.

2. Suominen Taipale AL, Alanen P, Helenius H, Nordblad A, Uutela A. Edentulism among Finnish adults of working age, 1978-1997. Community dentistry and oral epidemiology, 1999. 27(5):353-365.

3. Medina-Solís CE, Pérez-Núñez R, Maupomé G, Casanova-Rosado JF. Edentulism among Mexican adults aged 35 years and older and associated factors. American journal of public health, 2006. 96(9):1578-1581.

4. Erikson Erik H, Erikson Joan M. The life cycle completed (extended version). 1998: WW Norton \& Company. 61.

5. Cummer WE. An outline of the theory and practice of partial denture service. J Am Dent Assoc, 1922. 9(9):735-754.

6. Costa E. A simplified system for identifying partially edentoulous dental arches. J Prosthet Dent, 1974. 32(6):639-645.

7. Friedman J. The ABC classification of partial denture segments. J Prosthet Dent, 1953. 3(4): 517-524.

8. Applegate OC. The interdependence of periodontics and removable partial denture prosthesis. J Prosthet Dent, 1958. 8(2):269-281.

9. Al-Johany SS, Andres C. ICK classification system for partially edentulous arches. J Prosthodont, 2008. 17(6):502-507.

10. Patel JY, Vohra MY, Hussain JM. Assessment of Partially edentulous patients based on Kennedy's classification and its relation with Gender Predilection. International Journal of Scientific Study, 2014. 2(6): 32-36.

11. Hescot $P$, Roland R. Dental Health in France, 1990: DMF Scores for 6-, 9-, and 12-year-olds. 1991: French Union for Oral Health.

12. Bharathi M, Babu KR, Reddy G, Gupta N, Misuriya A,Vinod V. Partial Edentulism based on Kennedy's classifcation: An epidemiological study. J Contemp Dent Pract, 2013. 15(2): 229-231. 